\title{
A NOTE ON THE RETHLINGSHAFER SCALE OF TENDENCY-TO-CONTINUE
}

\author{
C. H. PETERSON \\ Institute of Child Welfare, University of Minnesota \\ Received March 10, 1942
}

In a series of recent articles $(3,4,5)$, Dr. Rethlingshafer compares the behavior following the interruption of activities of normal and feebleminded children of the same mental ages, in the attempt to test Lewin's theory of the rigidity of behavior in the feebleminded (2).

The basis of the majority of the comparisons made is the difference between the groups in terms of scale values of the classes of behavior distinguished by Dr. Rethlingshafer. The percents of behavior in each of 17 classifications were converted into standard deviation values.

This method of converting a classificatory system into a scale of equal units presupposes two conditions: (a) that the distribution is normal, and (b) that the classes are ordered in a hierarchical sequence (1, pp. 97, 99-102). The assumption of a normal distribution is the best assumption that can be made for an unknown distribution. The second assumption is the point at issue in the present . instance.

There is considerable doubt that the $\mathbf{1 7}$ classes are ordered from strong to weak in tendency-to-continue, as Dr. Rethlingshafer contends $(3$, p. 118). There are two reasons for this doubt. First, the order was determined by the judgment of only one individual, the experimenter. In ranking the order of items on a scale, the judgments of a large group of judges is necessary. The second, and perhaps more important reason for the doubt, lies in the possibility, or probability, that two variables are involved in the behavior classified in the scale.

As indications of tendency-to-continue, Dr. Rethlingshafer utilizes behavior in two situations: (a) response to being interrupted, or resistance to interruption, and (b) resumption of the interrupted activity when opportunity was provided. She apparently realized that these two kinds of behavior might not be identical or highly related, since in one report (5) she deals with this question, and concludes that the use of refusal-to-be-interrupted as a criterion of tendency-tocontinue is justified. Her findings do indicate that there is some relationship, but on the other hand they suggest that this relationship is not particularly close.

To the present writer the combination of these two kinds of behavior in a single scale is not justifiable, and results in a rank order that is not true for either the combined or double variable nor for either separately. Tendency to continue an activity may be measured by refusal to be interrupted in this activity. Tendency to return to an activity may be measured by its resumption after interruption. These two tendencies may or may not be correlated. It is quite 
logical to suppose that an individual who is easily absorbed in an activity, may, upon being interrupted and becoming engaged in another activity, become so absorbed in the second activity that resumption of the first will not take place, even though he was resistant to interruption. In other words, persistence in an activity as measured by resistance to interruption, and as measured by resumption of the activity after interruption, is not the same thing; one is not justified in assuming that both kinds of behavior measure the same thing and can be ranked on a single scale. It follows, then, that a scale containing both these types of behavior is a double-headed variable, which renders the ranking of the classes invalid. Scale values so obtained are thus inaccurate, and any further computations and comparisons involving these scores are spurious.

This defect of the scale may be one reason why the results were not clear cut, leading to the experimenter combining the results from feebleminded and normal children for comparison with adults in the third report (5).

Much of the difficulty of this, as well as of other work in comparing the rigidity of feebleminded and normal subjects inheres in the vagueness and complexity of Lewin's theory of feeblemindedness (2). Does rigidity consist in refusal to be interrupted, or in resumption of a task after interruption? Lewin, on the basis of Köpke's work, which indicated higher resumption in the feebleminded than in the normal, proposes that both are characteristic of the feebleminded, and goes to great pains to interpret both as rigidity. Rethlingshafer, however, found that the feebleminded were more resistant to interruption, but less apt to resume an activity than the normals. Köpke's results are thus not substantiated. A defect in Köpke's work was his failure to equate his subjects on mental age. It is difficult, however, to explain why he got 100 per cent resumption in feebleminded subjects and only 79 per cent resumption in normals, unless we assume that temporary distraction, rather than interruption, took place. Lewin, in his experiment, found that feebleminded subjects persisted longer in drawing moon faces before becoming satiated, but that they manifested more distractions. He interprets Köpke's results as indicating the fixity of the goal of the feebleminded. While it is perhaps true that the feebleminded show more fixity of purpose in an activity, on the other hand observation indicates that they do not show persistence in goal directed behavior if the goal is a distant one. Rethlingshafer's results support this observation. It is perhaps more economical to question Köpke's results, and to doubt whether interruption actually took place, particularly since they aren't supported by Rethlingshafer, than to laboriously attempt to make them fit into a theory, as Lewin has done. .

It appears that the confusion between persistence in an activity and persistence in returning to an activity as indications of rigidity are responsible for much of the disagreement of studies in this field. The rigid individual may be the one who refuses to be interrupted, but when once interruption is accomplished, he becomes absorbed in the new activity to the extent that the first is ignored or forgotten and not resumed. The individual who when interrupted can change to another activity, and then return to the former, though he shows persistence in clinging to a goal, is at the same time flexible, in that he can change 
under pressure and yet return. It is questionable if one could call resumption an indication of rigidity because it represents a persistence in activity toward a goal. Persistence is a term which has been applied to two different types of activity. It is possible that the situation might be clarified if the tendency-tocontinue in an ongoing activity were designated as perseveration, while the term persistence were reserved for the tendency-to-continue an activity after interruption. The first may be an indication of rigidity and characteristic of the feebleminded, while the latter is an indication of flexibility and may be more characteristic of the normal individual.

If the data of Dr. Rethlingshafer were reworked, using two scales instead of one, the results might be in line with this hypothesis. Since the original data is not included in the published reports, the writer is unable to complete this reanalysis.

\section{REFERENCES}

(1) Kelley, T. L.: Statistical Method. New York, Macmillan, 1934.

(2) LEwIN, K.: A Dynamic Theory of Personality. New York, McGraw-Hill, 1935.

(3) Rrthlingshafer, Dorothy: Measures of tendency-to-continue: I. Behavior of feebleminded and normal subjects following the interruption of activities. J. Genet. Psychol., 1941, 69, 109-124.

(4) - Measures of tendency-to-continue: II. Comparison of feebleminded and normal subjects when interrupted under different conditions. J. Genet. Psychol., $1941,69,125-138$.

(5) tendency-to-continue interrupted activities. J. Comp. Psychol., 1941, 32, 205-216. 